\title{
Electronic Markets Selection in Supply Chain with Uncertain Demand and Uncertain Price
}

\author{
Fengmei Yang, ${ }^{1}$ Yakun Wang, ${ }^{1}$ Jie Pei, ${ }^{2}$ and Jian $\mathrm{Li}^{2}$ \\ ${ }^{1}$ School of Science, Beijing University of Chemical Technology, Beijing 100029, China \\ ${ }^{2}$ School of Economics and Management, Beijing University of Chemical Technology, Beijing 100029, China
}

Correspondence should be addressed to Jian Li; lijian7776@126.com

Received 14 May 2014; Revised 21 July 2014; Accepted 28 July 2014

Academic Editor: Tsan-Ming Choi

Copyright (c) 2015 Fengmei Yang et al. This is an open access article distributed under the Creative Commons Attribution License, which permits unrestricted use, distribution, and reproduction in any medium, provided the original work is properly cited.

In recent years, more and more companies start online operation. Electronic market becomes a key component of some companies' strategy. Supply chain management is another key component of the strategy as being adopted by an increasing number of companies. There are many interactions between electronic market and supply chain. One of the key questions is to select one type of electronic market from the view of supply chain. This paper develops some models to explore the issue of selection between public electronic market and private electronic market in three scenarios where electronic market is used for buying, for selling, and for both selling and buying, respectively. In a public electronic market, neither the supplier nor the retailer is the owner of the electronic market. However, in a private electronic market, there is an owner that is either the supplier or the retailer. Besides demand uncertainty, we take into account the price uncertainty in electronic market. We explore the conditions under which the agent of supply chain selects one certain type of electronic market by comparing expected profits of supply chain members in different scenarios. Some sensitivity analyses are conducted to explore the impact of the customer demand, electronic market retail price, and e-market use fee on the selection of electronic market. Finally, some interesting managerial and academic insights are obtained.

\section{Introduction}

In recent years, electronic market (hereafter e-market) has received increasing attention from industry and more and more companies start online operation. For example, http://www.suning.com/ created his first e-commerce platform for online shopping in China in 2010. In 2013, the turnover of China B2B market was 8.2 trillion with more than 30 percent year-on-year growths. With the growth of e-commerce, e-market has been always one of the focuses in academia. Some details regarding business concept of electronic commerce can be seen in Kumar and Raheja [1].

Supply chain management is another strategy adopted by an increasing number of companies. Along with the ecommerce growth, e-market has a strong influence on supply chain management. Many papers in the literature explored the interaction between e-market and supply chain. For example, Peleg et al. [2] researched three procurement strategies to provide policies for supplier when there is an e-market.
They showed that supplier can make use of e-market to get high income. Seifert et al. [3] quantified the benefits of using online spot market from a supply chain perspective. Their results demonstrated that companies using online spot market can get higher service level and higher variability in profits than companies who do not use online spot market. Choi et al. [4] coordinated the supply chain by return policy and the return products were sold at a higher price to the supplier in e-market. Their results made it clear that the expected profit in e-market is always larger than the traditional market. Ganeshan et al. [5] showed that trading products either in the electronic spot market or via derivate instruments can get optimal procurement portfolios and mitigate risk. Standing et al. [6] summarized twelve years of research on e-market places since 1997 and pointed out the relative lack of papers on the organisational implications of managing e-market places. Khanam [7] noted that e-market has several features to increase user friendliness. Ning et al. [8] discussed the coordinate markdown policy when e-market is introduced besides 
the traditional market and showed that e-market is a benefit for supply chain in terms of the expected profit improvement. But e-market may have several disadvantages compared with traditional market from Kacen et al.s [9] research such as shipping and handling charges and good uncertainty. So more studies containing comprehensive characteristics on emarket are needed. Narenji et al. [10] introduced evolutionary game theory in finding the price and delivery time strategy equilibrium when supply chain is centralized and decentralized. Their conclusions demonstrated that supply chain with e-market is better than that with traditional market in most scenarios. Maity and Dass [11] helped us in making supply chain choice between traditional market and e-market from the view of media richness theory containing both product characteristics and channel characteristics. Their study showed that customers prefer e-market over other channels that have higher or lower media richness.

As it can be seen above, e-market plays an important role in supply chain management and scholars have attached great importance on it. But e-market is such a significant market that needs a more detailed analysis to dig up its huge potential. For example, as a matter of fact, both price uncertainty and demand uncertainty exist in supply chain. It is essential to take both uncertainties into consideration. However, most of the papers in this field focus only on one of the two uncertainties. For instance, Wang and Benaroch [12] only took the demand uncertainty into consideration and analyzed the decision of supply chain members who use or do not use emarket. Ghose and Yao [13] considered the uncertain price and found that the "law of one price" can prevail. There are also a few papers that take both uncertainties into account. For example, Inderfurth et al. [14] explored the channel selection with considering random price or stochastic demand in their sourcing model where price and demand are all have cumulative distribution, density function, expected value, and standard deviation.

What is more, there are different types of e-markets. For example, according to the owner who builds and operates the e-market, the e-market can be classified into three types, that is, third party-driven, buyer-driven, and seller-driven (Shon et al. [15]). Furthermore, some e-markets are used only for buying, only for selling, or for both selling and buying. The right selection of e-market is critical for a supply chain. Xing et al. [16] investigated the supply chain members' strategies in decentralized supply chain in B2B electronics market where the supplier is the owner. Truong et al. [17] showed that retailers' expectations of benefits differ significantly between different public and private market. From the point of Khanam's [7] research, the owner who drives the e-market charges the other members and the charge impacts the retail price of e-market and indirectly affects earnings. Pei et al. [18] obtained the expected profit when there is an owner in three different kinds of e-markets. Li et al. [19] identified the conditions under which the supplier would join public or private market. However, neither of the above two papers obtains the close form of the optimal order quantity and which specific kind of e-market the supplier should join.

Motivated by the above, we study the e-markets selection from the view of supply chain between public e-market and private e-market with uncertain demand and uncertain price in three different scenarios where e-market is used for buying, for selling, or for both selling and buying, respectively. The close form of the optimal order quantity of retailer and the profit of supply chain members in different e-markets is derived in the case of customer demand and retail price following uniform distribution. The comparison between expected profits of e-markets can help supply chain members trade-off between public e-market and private e-market in three scenarios. Some sensitivity analyses are also conducted to explore the impact of the customer demand, the price of emarket, and the e-market use fee on the e-market selection. In the following text, EB, ES, and EM are used to denote emarket for buying, for selling, and for both selling and buying, respectively.

The rest of this paper is organized as follows. The next section describes the notations and the assumptions of the problem. Section 3 explores the optimal strategies of the retailer when e-market is managed by a third-party manager, the supplier, and the retailer, respectively. The trade-off between public e-market and private e-market in three supply chain structures is discussed. Section 4 examines the impact of the various e-market parameters via sensitivity analysis. The last section offers concluding remarks as well as some opportunities for future research. All the proofs of the theoretical results are given in the Appendix.

\section{Notations and Assumptions}

We consider a two-echelon supply chain consisting of a single supplier and a single retailer. There are two kinds of markets: the traditional market and the e-market. Product is the newsvendor type with short life-cycle, short selling season, and uncertain demand. The retailer cannot make any replenishment from the traditional market during selling season due to the long lead time. However, it is assumed that the retailer can make emergency replenishment from the emarket if they can pay more. Some papers can be given to illustrate that the assumption is a good approximation of reality. For example, Fu et al. [20] studied the newsvendor model with multiple options of expediting options. They argued that various expediting options can help satisfy the demand with a different more expensive price than early order. Some other studies such as $[21,22]$ also pointed out that a higher price can make a shorter lead time. Moreover, due to the fleetness to deal with information in e-market, the product in e-market can be assumed as a kind of expediting options with higher price and zero lead time.

The sequence of the events is as follows.

The retailer decides his order quantity $q$ before selling season. He can forecast the cumulative distribution function $F_{d}(\cdot)$ of the demand. When selling season comes, the retailer fills demand $x$ by quantity $q$.

In traditional market, if the realized demand $x$ is higher than the initial order quantity $q$, the retailer will face lost sales with an additional penalty cost $g$. If the demand is lower than $q$, all unsold products will be salvaged at salvage value $v$.

If the retailer can use the e-market, there are three cases as follows. 
Case 1. When e-market is used only for buying, extra demand $x-q$ can be filled via e-market. However, if the retailer has excess inventory at the end of selling season, it could only be salvaged at unit price $v$ in the traditional market.

Case 2. When the e-market is used only for selling, the retailer can sell products via both traditional market and emarket. All excess inventory $q-x$ could be sold at unit price $p_{e}$ via the e-market. However, there might be a stock out $x-q$ since the retailer only uses traditional market to order.

Case 3. When the e-market is used for both selling and buying, the retailer can fill all the demand $x$ via traditional market and via e-market. He can make emergency replenishment to fill the demand via the e-market. In addition, the retailer can sell all excess inventory $q-x$ at unit price $p_{e}$ via the e-market.

Definitions of the notation and assumptions of this paper are presented below.

\subsection{Notations}

We have the following:

$p_{r}:$ unit retail price in traditional market;

$p_{e}$ : unit retail price in e-market, nonnegative continuous random variable;

$\mu_{e}$ : the mean of $p_{e}$;

$f_{e}(\cdot)$ : probability density function of $p_{e}$;

$F_{e}(\cdot)$ : cumulative distribution function of $p_{e}$;

$x$ : customer demand, nonnegative continuous random variable;

$\mu_{d}$ : the mean of $x$;

$f_{d}(\cdot)$ : probability density function of $x$;

$F_{d}(\cdot)$ : cumulative distribution function of $x$;

q: retailer's order quantity;

c: unit production cost of supplier;

$w$ : unit wholesale price in traditional market;

$g$ : unit lost sales cost;

$v$ : unit salvage value;

$M$ : the upper production capacity limit of supplier;

$m$ : the ratio of the e-market use fee to the gross transaction in the e-market, that is, the e-market user should pay a percentage of part of their gross transaction in e-market as the e-market use fee to the e-market owner.

\subsection{Assumptions}

(A1) To avoid the trial cases, it is assumed that the following inequations hold: $0<v<c<w<p_{r}, g>0$, $q<M$.
(A2) Demand $x$ and e-market price $p_{e}$ are two-dimension uniform (2DU) distributed. It is assumed that $x \sim$ $U\left(\mu_{d}-r, \mu_{d}+r\right), p_{e} \sim U\left(\mu_{e}-s, \mu_{e}+s\right)$, and $\left(x, p_{e}\right) \sim$ $U\left(\mu_{d}-r, \mu_{d}+r ; \mu_{e}-s, \mu_{e}+s\right)$.

$\left(\mathrm{A} 2^{\prime}\right)$ To see whether the findings under the premise of twodimension uniform distribution still hold for more general case, we consider an extension of the model in the numerical example to the case that demand $x$ and e-market price $p_{e}$ are bivariate normal (BN). There is $\left(x, p_{e}\right) \sim \mathrm{BN}\left(\mu_{d}, \mu_{e}, \sigma_{d}, \sigma_{e}, \rho\right)$ where $\rho \geq 0$.

\section{Model Formulation and Analysis}

In this section, we develop and analyze the models in different scenarios, such as public e-market, private e-market, and e-market for buying, for selling, and for both selling and buying, respectively.

Suppose the retailer or the supplier wants to deal with lost sales or/and excess inventory via e-market. The user should pay a fee for the transaction in the e-market to the owner. For example, in a public e-market, the e-market use fee should be paid to the third party who is in charge of the e-market. In a private e-market, if the supplier is the owner, the retailer who needs to join the e-market has to pay a e-market use fee to the supplier, and vice versa.

In each model, expected profits and optimal order quantity are derived in the case that demand and retail price are uniform distribution. By comparing the expected profits of the supply chain agents in these models, we obtain the condition under which the supply chain member chooses a public e-market or a private e-market and analyze the optimal type of e-market should be built. We find that e-market use fee ratio $m$ and parameters of uncertain price and demand are all important parameters in market selection decision-making.

\subsection{Supply Chain Models in EB}

3.1.1. Supply Chain Models in Public EB. If e-market is a public e-market and is used for only buying, the retailer can make an emergency order from the supplier to fill the excess demand via the e-market. Both the retailer and the supplier will pay e-market use fee to the third party that is in charge of the market.

Suppose $\Delta q_{\mathrm{EB}}$ is the emergency order of the retailer via e-market, that is, the product quantity the supplier sells in e-market besides the order quantity of retailer $q_{\mathrm{EB}}$. The expected profit function of the supplier is given by

$$
\begin{aligned}
\Pi_{\mathrm{EB}}^{S} & \left(q_{\mathrm{EB}}+\Delta q_{\mathrm{EB}}\right) \\
= & -c\left(q_{\mathrm{EB}}+\Delta q_{\mathrm{EB}}\right)+w q_{\mathrm{EB}} \\
& +(1-m) \int_{-\infty}^{\infty} \Delta q_{\mathrm{EB}} p_{e} f_{e}\left(p_{e}\right) d p_{e} \\
= & -c\left(q_{\mathrm{EB}}+\Delta q_{\mathrm{EB}}\right)+w q_{\mathrm{EB}}+(1-m) \mu_{e} \Delta q_{\mathrm{EB}} \\
= & (w-c) q_{\mathrm{EB}}+\left[(1-m) \mu_{e}-c\right] \Delta q_{\mathrm{EB}} .
\end{aligned}
$$


It is obvious that if $m<1-\left(c / \mu_{e}\right)$, the supplier will get more profit than in traditional market and would like to join the e-market. by

Then the expected profit function of the retailer is given

$$
\begin{aligned}
\Pi_{\mathrm{EB}}^{R}(q)= & -w q+\int_{-\infty}^{q} p_{r} x f_{d}(x) d x \\
& +\int_{-\infty}^{q} v(q-x) f_{d}(x) d x+\int_{q}^{\infty} p_{r} q f_{d}(x) d x \\
& -\int_{q}^{\infty} d x \int_{-\infty}^{\infty}\left(p_{e}-p_{r}\right)(x-q) f_{d, e}\left(x, p_{e}\right) d p_{e} \\
& -\int_{q}^{\infty} d x \int_{-\infty}^{\infty} m p_{e}(x-q) f_{d, e}\left(x, p_{e}\right) d p_{e} .
\end{aligned}
$$

It is straightforward to prove that $\Pi_{\mathrm{EB}}^{R}(q)$ is concave as in [18]. By using the first- and second-order optimality conditions, we can obtain the following equation that the optimal order quantity of the retailer denoted by $q_{\mathrm{EB}}^{*}$ is subject to

$$
w=v F_{d}\left(q_{\mathrm{EB}}^{*}\right)+\int_{q_{\mathrm{EB}}^{*}}^{+\infty} \int_{-\infty}^{+\infty}(1+m) p_{e} f_{d, e}\left(x, p_{e}\right) d p_{e} d x .
$$

When demand and retail price in e-market are 2DU distributed, the close form of the optimal order quantity is given by

$$
q_{\mathrm{EB}}^{*}=\mu_{d}+\frac{r\left(2 w-v-(1+m) \mu_{e}\right)}{v-(1+m) \mu_{e}} .
$$

And the optimal expected profit of the retailer is obtained as follows:

$$
\begin{aligned}
\Pi_{\mathrm{EB}}^{R *}= & \frac{v-(1+m) \mu_{e}}{4 r} q_{\mathrm{EB}}^{* 2} \\
& +\frac{1}{2 r}\left[(1+m) \mu_{e}\left(\mu_{d}+r\right)-v\left(\mu_{d}-r\right)-2 r w\right] q_{\mathrm{EB}}^{*} \\
& +p_{r} \mu_{d}+\frac{v}{4 r}\left(\mu_{d}-r\right)^{2}-\frac{\mu_{e}}{4 r}(1+m)\left(\mu_{d}+r\right)^{2} \\
= & p_{r} \mu_{d}-w \mu_{d}+r v-r w+\frac{r(v-w)^{2}}{(1+m) \mu_{e}-v} .
\end{aligned}
$$

\subsubsection{Supply Chain Models in Private EB}

(a) Supplier as the Owner in EB. If e-market is managed by the supplier and used for only buying, the retailer can make an emergency order from the supplier to fill the excess demand via the e-market. The retailer will pay an e-market use fee to the supplier that is in charge of the e-market.

In decentralized supply chain, the profit function of the retailer and the optimal order quantity are the same with those in the public EB. However, the supplier's profit function changes into the following formulation:

$$
\begin{aligned}
\Pi_{\mathrm{EB}}^{S} & \left(q_{\mathrm{EB}}+\Delta q_{\mathrm{EB}}\right) \\
= & -c\left(q_{\mathrm{EB}}+\Delta q_{\mathrm{EB}}\right)+w q_{\mathrm{EB}} \\
& +(1+m) \int_{-\infty}^{\infty} \Delta q_{\mathrm{EB}} p_{e} f_{e}\left(p_{e}\right) d p_{e} \\
= & (w-c) q_{\mathrm{EB}}+\left((1+m) \mu_{e}-c\right) \Delta q_{\mathrm{EB}} .
\end{aligned}
$$

As seen from the above, if the retailer is not the owner of the $\mathrm{EB}$, the expected profit of the retailer is independent of the owner of the EB. But the supplier would prefer his own private $\mathrm{EB}$ to public EB if ignoring the operating costs.

(b) Retailer as the Owner in EB. If e-market is managed by the retailer and only used for buying, the retailer can make an emergency order from the supplier to fill the excess demand via the e-market. Supplier should pay the retailer e-market use fee and his expected profit function is the same with (1). The expected profit function of retailer in decentralized supply chain is given by

$$
\begin{aligned}
\Pi_{\mathrm{EB}}^{R}(q)= & -w q+\int_{-\infty}^{q} p_{r} x f_{d}(x) d x \\
& +\int_{-\infty}^{q} v(q-x) f_{d}(x) d x+\int_{q}^{\infty} p_{r} q f_{d}(x) d x \\
& -\int_{q}^{\infty} d x \int_{-\infty}^{\infty}\left(p_{e}-p_{r}\right)(x-q) f_{d, e}\left(x, p_{e}\right) d p_{e} \\
& +\int_{q}^{\infty} d x \int_{-\infty}^{\infty} m p_{e}(x-q) f_{d, e}\left(x, p_{e}\right) d p_{e} .
\end{aligned}
$$

We can derive the optimal order quantity as (8). Consider the following:

$$
w=v F_{d}\left(q_{\mathrm{EB}}^{*}\right)+\int_{q_{\mathrm{EB}}^{*}}^{+\infty} \int_{-\infty}^{+\infty}(1-m) p_{e} f_{d, e}\left(x, p_{e}\right) d p_{e} d x .
$$

If demand and retail price in e-market are 2DU distributed, the close form of optimal order quantity and expected profit of retailer are given by

$$
\begin{gathered}
q_{\mathrm{EB}}^{*}=\mu_{d}+\frac{r\left(2 w-v-(1-m) \mu_{e}\right)}{v-(1-m) \mu_{e}} . \\
\Pi_{\mathrm{EB}}^{R *}=\frac{v-(1-m) \mu_{e}}{4 r} q_{\mathrm{EB}}^{* 2} \\
+\frac{1}{2 r}\left[(1-m) \mu_{e}\left(\mu_{d}+r\right)-v\left(\mu_{d}-r\right)-2 r w\right] q_{\mathrm{EB}}^{*} \\
+p_{r} \mu_{d}+\frac{v}{4 r}\left(\mu_{d}-r\right)^{2}-\frac{\mu_{e}}{4 r}(1-m)\left(\mu_{d}+r\right)^{2} \\
=p_{r} \mu_{d}-w \mu_{d}+r v-r w+\frac{r(v-w)^{2}}{(1-m) \mu_{e}-v} .
\end{gathered}
$$


Retailer's expected profit has increased when formulation (7) minus (2) if the in two expressions are at the same value. It means that retailer would rather choose his own private e-market than public e-market in EB when operating cost is smaller than the additional income $C_{\mathrm{EB}}$, where

$$
C_{\mathrm{EB}}=\int_{q}^{\infty} d x \int_{-\infty}^{\infty} 2 m p_{e}(x-q) f_{d, e}\left(x, p_{e}\right) d p_{e} .
$$

If demand and retail price in e-market are 2DU distributed, the additional revenue in the e-market controlled by retailer is given by

$$
C_{\mathrm{EB}}=\frac{2 m \mu_{e} r(v-w)^{2}}{\left(\mu_{e}-v\right)\left(\mu_{e}-v+2 m \mu_{e}\right)} .
$$

The above two models indicate that e-market owner would enjoy more profit in private EB if additional income is larger than the construction and operation cost of EB.

\subsection{Supply Chain Models in ES}

3.2.1. Supply Chain Models in Public ES. If e-market is managed by a third-party manager, the supplier's profit function is as follows since ES involves the retailer and the supplier cannot join ES:

$$
\Pi_{\mathrm{ES}}^{\mathrm{S}}\left(q_{\mathrm{ES}}\right)=-c q_{\mathrm{ES}}+w q_{\mathrm{ES}} .
$$

The profit function of retailer and the optimal order quantity in decentralized supply chain are given by

$$
\begin{aligned}
\Pi_{\mathrm{ES}}^{R}(q)= & -w q+\int_{-\infty}^{q} p_{r} x f_{d}(x) d x \\
& +\int_{-\infty}^{q} d x \int_{-\infty}^{\infty} p_{e}(q-x) f_{d, e}\left(x, p_{e}\right) d p_{e} \\
& +\int_{q}^{\infty} p_{r} q f_{d}(x) d x-\int_{q}^{\infty} g(x-q) f_{d}(x) d x \\
& -m \int_{-\infty}^{q} d x \int_{-\infty}^{\infty} p_{e}(q-x) f_{d, e}\left(x, p_{e}\right) d p_{e} . \\
w= & \left(p_{r}+g\right)\left(1-F_{d}\left(q_{\mathrm{ES}}^{*}\right)\right) \\
& +(1-m) \int_{-\infty}^{q_{\mathrm{ES}}^{*}} \int_{-\infty}^{+\infty} p_{e} f_{d, e}\left(x, p_{e}\right) d p_{e} d x .
\end{aligned}
$$

When demand and retail price in e-market are 2DU distributed, the optimal order quantity and expected profit of the retailer are given by

$$
\begin{gathered}
q_{\mathrm{ES}}^{*}=\frac{2 r w-\left(p_{r}+g\right)\left(\mu_{d}+r\right)+\mu_{e}(1-m)\left(\mu_{d}-r\right)}{(1-m) \mu_{e}-p_{r}-g}, \\
\Pi_{\mathrm{ES}}^{R *}=\frac{1}{4 r}\left((1-m) \mu_{e}-p_{r}-g\right) q_{\mathrm{ES}}^{* 2}
\end{gathered}
$$

$$
\begin{aligned}
+ & \frac{1}{2 r}\left[\left(p_{r}+g\right)\left(\mu_{d}+r\right)\right. \\
& \left.\quad-\mu_{e}(1-m)\left(\mu_{d}-r\right)-2 r w\right] q_{\mathrm{ES}}^{*} \\
+ & \frac{1}{4 r}\left[\left((1-m) \mu_{e}-p_{r}\right)\left(\mu_{d}-r\right)^{2}-g\left(\mu_{d}+r\right)^{2}\right] \\
= & p_{r} \mu_{d}+(1-m) \mu_{e} r-\mu_{d} w-r w \\
+ & \frac{r\left((1-m) \mu_{e}-w\right)^{2}}{g+p_{r}-(1-m) \mu_{e}} .
\end{aligned}
$$

3.2.2. Supply Chain Models in Private ES. In this scenario, only the retailer is the owner of the supply chain. Then the profit function of the retailer is given by

$$
\begin{aligned}
\Pi_{\mathrm{ES}}^{R}(q)= & -w q+\int_{-\infty}^{q} p_{r} x f_{d}(x) d x \\
& +\int_{-\infty}^{q} d x \int_{-\infty}^{\infty} p_{e}(q-x) f_{d, e}\left(x, p_{e}\right) d p_{e} \\
& +\int_{q}^{\infty} p_{r} q f_{d}(x) d x \\
& -\int_{q}^{\infty} g(x-q) f_{d}(x) d x .
\end{aligned}
$$

The optimal order quantity should satisfy

$$
\begin{aligned}
w= & \left(p_{r}+g\right)\left(1-F_{d}\left(q_{\mathrm{ES}}^{*}\right)\right) \\
& +\int_{-\infty}^{q_{\mathrm{ES}}^{*}} \int_{-\infty}^{+\infty} p_{e} f_{d, e}\left(x, p_{e}\right) d p_{e} d x .
\end{aligned}
$$

When demand and retail price in e-market are 2DU distributed, the optimal order quantity and expected profit of the retailer are given by

$$
\begin{aligned}
q_{\mathrm{ES}}^{*} & =\frac{2 r w-\left(p_{r}+g\right)\left(\mu_{d}+r\right)+\mu_{e}\left(\mu_{d}-r\right)}{\mu_{e}-p_{r}-g} \\
\Pi_{\mathrm{ES}}^{R *}= & \frac{1}{4 r}\left(\mu_{e}-p_{r}-g\right) q_{\mathrm{ES}}^{* 2} \\
& +\frac{1}{2 r}\left[\left(p_{r}+g\right)\left(\mu_{d}+r\right)-\mu_{e}\left(\mu_{d}-r\right)-2 r w\right] q_{\mathrm{ES}}^{*} \\
& +\frac{1}{4 r}\left[\left(\mu_{e}-p_{r}\right)\left(\mu_{d}-r\right)^{2}-g\left(\mu_{d}+r\right)^{2}\right] \\
= & \mu_{d} p_{r}+\mu_{e} r-\mu_{d} w-r w+\frac{r\left(\mu_{e}-w\right)^{2}}{g-\mu_{e}+p_{r}} .
\end{aligned}
$$

The retailer's additional revenue is obtained as follows:

$$
C_{\mathrm{ES}}=\int_{-\infty}^{q} d x \int_{-\infty}^{\infty} m p_{e}(q-x) f_{d, e}\left(x, p_{e}\right) d p_{e} .
$$


If demand and retail price in e-market are $2 \mathrm{DU}$ distributed, the expected additional revenue when the retailer builds ES is given by

$$
\begin{aligned}
C_{\mathrm{ES}} & =m \mu_{e} r+\frac{r\left(\mu_{e}-w\right)^{2}}{g-\mu_{e}+p_{r}}-\frac{r\left((1-m) \mu_{e}-w\right)^{2}}{g-(1-m) \mu_{e}+p_{r}} \\
& =\frac{m \mu_{e} r(g+p r-w)^{2}}{\left(g-\mu_{e}+p_{r}\right)\left(g-(1-m) \mu_{e}+p_{r}\right)} .
\end{aligned}
$$

It turned out that the retailer in ES will prefer private emarkets to public e-market if $\left(g-\mu_{e}+p_{r}\right)\left(g-(1-m) \mu_{e}+p_{r}\right)>0$ and $C_{\mathrm{ES}}$ is larger than the construction and operation cost of ES.

\subsection{Supply Chain Models in EM}

3.3.1. Supply Chain Models in Public EM. When the third party builds EM and supply chain members join EM independently, the profit of the supplier is given by

$$
\begin{aligned}
& \Pi_{\mathrm{EM}}^{S}\left(q_{\mathrm{EM}}+\Delta q_{\mathrm{EM}}\right) \\
& \quad=(w-c) q_{\mathrm{EB}}+\left[(1-m) \mu_{e}-c\right] \Delta q_{\mathrm{EB}} .
\end{aligned}
$$

The retailer's expected profit is given by

$$
\begin{aligned}
& \Pi_{\mathrm{EM}}^{R}(q) \\
& =(1-m) \int_{-\infty}^{q} d x \int_{-\infty}^{\infty} p_{e}(q-x) f_{d, e}\left(x, p_{e}\right) d p_{e} \\
& \quad-(1+m) \int_{q}^{\infty} d x \int_{-\infty}^{\infty} p_{e}(x-q) f_{d, e}\left(x, p_{e}\right) d p_{e} \\
& \quad-w q+p_{r} \mu_{d} .
\end{aligned}
$$

The optimal order quantity $q_{\mathrm{EM}}^{*}$ should satisfy

$$
w=(1-m) \mu_{e}+2 m \int_{q_{\mathrm{EM}}^{*}}^{\infty} d x \int_{-\infty}^{\infty} p_{e} f_{d, e}\left(x, p_{e}\right) d p_{e} .
$$

When demand and retail price in e-market are $2 \mathrm{DU}$ distributed, the optimal order quantity and the expected profit of retailer are given by

$$
\begin{gathered}
q_{\mathrm{EM}}^{*}=\mu_{d}+\frac{\left(\mu_{e}-w\right) r}{m \mu_{e}} \\
\Pi_{\mathrm{EM}}^{R *}=-\frac{m \mu_{e}}{2 r} q_{\mathrm{EM}}^{*}+\left[\frac{m \mu_{e} \mu_{d}}{r}+\mu_{e}-w\right] q_{\mathrm{EM}}^{*} \\
+p_{r} \mu_{d}-\mu_{e} \mu_{d}-\frac{m \mu_{e}}{2 r}\left(\mu_{d}^{2}+r^{2}\right) \\
=\mu_{d}\left(p_{r}-w\right)-\frac{m \mu_{e} r}{2}+\frac{r\left(\mu_{e}-w\right)^{2}}{2 m \mu_{e}} .
\end{gathered}
$$

\subsubsection{Supply Chain Models in Private EM}

(a) Supplier as the Owner in EM. Since the retailer is not the owner of the supply chain, his decision making is not affected by public and private e-markets. The profit function and the optimal order quantity of the retailer are the same as that in the supply chain managed by third-party manager. The profit function of the supplier in this case is given by

$$
\begin{aligned}
& \Pi_{\mathrm{EM}}^{S}\left(q_{\mathrm{EM}}+\Delta q_{\mathrm{EM}}\right) \\
& \quad=(w-c) q_{\mathrm{EM}}+\left((1+m) \mu_{e}-c\right) \Delta q_{\mathrm{EM}} .
\end{aligned}
$$

It can be obtained from (22) and (27) that if the supplier's profit increases, he will build his private e-market ignoring the operating costs.

(b) Retailer as the Owner in EM. If the retailer is the owner in $\mathrm{EM}$, the profit function of the retailer in EM is given by

$$
\begin{aligned}
\Pi_{\mathrm{EM}}^{R}(q)= & \int_{-\infty}^{q} d x \int_{-\infty}^{\infty} p_{e}(q-x) f_{d, e}\left(x, p_{e}\right) d p_{e} \\
& -\int_{q}^{\infty} d x \int_{-\infty}^{\infty} p_{e}(x-q) f_{d, e}\left(x, p_{e}\right) d p_{e} \\
& +\int_{q}^{\infty} d x \int_{-\infty}^{\infty} m p_{e}(x-q) f_{d, e}\left(x, p_{e}\right) d p_{e} \\
& -w q+p_{r} \mu_{d} .
\end{aligned}
$$

When demand and retail price in e-market are 2DU distributed, $\Pi_{\mathrm{EM}}^{R}(q)$ is not concave and the expected profit is given by

$$
\begin{aligned}
\Pi_{\mathrm{EM}}^{R}= & \frac{m \mu_{e}}{4 r} q_{\mathrm{EM}}^{*}+\left[\mu_{e}-w-\frac{m \mu_{e}}{2 r}\left(\mu_{d}+r\right)\right] q_{\mathrm{EM}}^{*} \\
& +p_{r} \mu_{d}-\mu_{e} \mu_{d}+\frac{m \mu_{e}}{4 r}\left(\mu_{d}+r\right)^{2} .
\end{aligned}
$$

The abscissa of this reverse parabola's symmetric axis is $\mu_{d}+r-\left(2 r / m \mu_{e}\right)\left(\mu_{e}-w\right)$.

Suppose that supply is adequate, that is, $\mu_{d}+r<M$. If $\mu_{d}+r-\left(2 r / m \mu_{e}\right)\left(\mu_{e}-w\right)<\left(\mu_{d}+r\right) / 2$, the optimal order quantity is $q_{\mathrm{EM}}^{*}=\mu_{d}+r$, else the retailer would choose to buy and sell in the e-market he builds without taking any orders from traditional suppliers, that is, $q_{\mathrm{EM}}^{*}=0$. Hence there is

$$
q_{\mathrm{EM}}^{*}= \begin{cases}\mu_{d}+r, & m<\frac{4 r\left(\mu_{e}-w\right)}{\mu_{e}\left(\mu_{d}+r\right)}, \\ 0, & \text { else. }\end{cases}
$$

The expected profit of retailer is given by

$$
\Pi_{\mathrm{EM}}^{R *}= \begin{cases}\left(\mu_{e}-w\right) r+\left(p_{r}-w\right) \mu_{d}, & m<\frac{4 r\left(\mu_{e}-w\right)}{\mu_{e}\left(\mu_{d}+r\right)}, \\ \left(p_{r}-\mu_{e}\right) \mu_{d}+\frac{m \mu_{e}}{4 r}\left(\mu_{d}+r\right)^{2}, & \text { else. }\end{cases}
$$

The additional revenue of the retailer is given by

$$
\begin{aligned}
C_{\mathrm{EM}}= & \int_{-\infty}^{q} d x \int_{-\infty}^{\infty} m p_{e}(q-x) f_{d, e}\left(x, p_{e}\right) d p_{e} \\
& +\int_{q}^{\infty} d x \int_{-\infty}^{\infty} 2 m p_{e}(x-q) f_{d, e}\left(x, p_{e}\right) d p_{e} .
\end{aligned}
$$


When demand and retail price in e-market are $2 \mathrm{DU}$ distributed, the additional revenue of the retailer is given by

$$
C_{\mathrm{EM}}= \begin{cases}\left(\mu_{e}-w\right) r+\frac{m \mu_{e} r}{2} & m<\frac{4 r\left(\mu_{e}-w\right)}{\mu_{e}\left(\mu_{d}+r\right)} \\ -\frac{r\left(\mu_{e}-w\right)^{2}}{2 m \mu_{e}}, & \\ \left(w-\mu_{e}\right) \mu_{d}+\frac{m \mu_{e} r}{2} & \text { else. } \\ -\frac{r\left(\mu_{e}-w\right)^{2}}{2 m \mu_{e}}+\frac{m \mu_{e}\left(\mu_{d}+r\right)^{2}}{4 r}, & \end{cases}
$$

Hence, the retailer would build his private e-market if the additional income $C_{\mathrm{EM}}$ is larger than the construction and operation cost of an e-market.

3.4. The Choice between EB, ES, and EM. From the analyses above, it can be found that both supplier and retailer prefer their private e-market. In this section, we intend to analyze which kind of private e-market should supplier and retailer build.

3.4.1. Supplier as the Owner. When the supplier is the owner of EB or EM, he would compare the expected profit in EB and EM. The profits are (6) and (27) if demand and retail price in e-market are 2DU distributed. Equations show that supplier's profits are determined by the optimal order quantity in (4) and (25). There is the following theorem.

Theorem 1. If $m>1-\left(v / \mu_{e}\right)$, the supplier would choose EM as his own e-market. If $0<m<1-\left(v / \mu_{e}\right)$, the supplier would choose EB as his own e-market. If $m=1-\left(v / \mu_{e}\right)$, it makes no difference for the supplier to choose EB or EM.

From Theorem 1, it can be found that the supplier's decision depends on the unit salvage value $v$, the unit expected retail price $\mu_{e}$, and the e-market use fee ratio $m$. For any given $m$ and $v$, the supplier's choice will change from EM to EB as the expected e-market price $\mu_{e}$ increases. Because as $\mu_{e}$ increases, shutting down the selling channel can help in increasing expected sales in EB and earn more profit in EB than that in ES. For any given $\mu_{e}$ and $v$, the supplier will choose EM and give up EB as $m$ increases since the supplier can charge more e-market use fee from the retailer in EM.

3.4.2. Retailer as the Owner. When the retailer is the owner of $\mathrm{EB}, \mathrm{ES}$, or EM, the expected profits are as (10), (19), and (31), respectively. The retailer would compare the expected profit in EB, ES, and EM when he makes choice. There are the following theorems.
Theorem 2. If $m$ and other parameters satisfy one of the following three conditions, the retailer would prefer EM as his own e-market to $E B$ :

(1)

$$
\begin{gathered}
\mu_{e}+v-2 w>0 \\
m<\frac{4 w v+\mu_{e}^{2}-2 v^{2}-w^{2}-2 w \mu_{e}}{\mu_{e}\left(\mu_{e}+v-2 w\right)} \wedge \frac{4 r\left(\mu_{e}-w\right)}{\mu_{e}\left(\mu_{d}+r\right)}
\end{gathered}
$$

(2)

$$
\begin{gathered}
\beta^{2}-4 \alpha \gamma>0, \\
\frac{4 r\left(\mu_{e}-w\right)}{\mu_{e}\left(\mu_{d}+r\right)}<m<\frac{\mu_{e}-v}{\mu_{e}} \wedge \frac{-\beta+\sqrt{\beta^{2}-4 \alpha \gamma}}{2 \alpha} ;
\end{gathered}
$$

(3)

$$
\begin{gathered}
\beta^{2}-4 \alpha \gamma<0, \\
m>\frac{4 r\left(\mu_{e}-w\right)}{\mu_{e}\left(\mu_{d}+r\right)},
\end{gathered}
$$

where

$$
\begin{gathered}
\alpha=\mu_{d}^{2} \mu_{e}^{2}+2 r \mu_{d} \mu_{e}^{2}+\mu_{e}^{2} r^{2} \\
\beta=\mu_{d}^{2} \mu_{e} v-\mu_{e}^{2} r^{2}-6 r \mu_{d} \mu_{e}^{2}-\mu_{d}^{2} \mu_{e}^{2}+5 v \mu_{e} r^{2}-4 w \mu_{e} r^{2} \\
+2 r v \mu_{d} \mu_{e}+4 r w \mu_{d} \mu_{e}, \\
\gamma=4 r \mu_{d} \mu_{e}^{2}-4 v \mu_{e} r^{2}+4 w \mu_{e} r^{2}-4 r v \mu_{d} \mu_{e}-4 r w \mu_{d} \mu_{e} \\
+8 r^{2} v^{2}-12 r^{2} v w+4 r^{2} w^{2}+4 r v w \mu_{d} .
\end{gathered}
$$

Theorem 3. If $m$ and other parameters satisfy one of the following two conditions, the retailer would choose EM as his own e-market instead of ES:

(1)

$$
\begin{gathered}
m<\frac{4 r\left(\mu_{e}-w\right)}{\mu_{e}\left(\mu_{d}+r\right)}, \\
2 \mu_{e} r<\frac{r\left(\mu_{e}-w\right)^{2}}{g-\mu_{e}+p_{r}} ;
\end{gathered}
$$

(2)

$$
m>\frac{4 r\left(\mu_{e}-w\right)}{\mu_{e}\left(\mu_{d}+r\right)} \vee \eta
$$

where $\eta=4 r\left(\left(\mu_{e}-w\right)^{2}+w\left(\mu_{d}+r\right)-\mu_{e}\left(\mu_{d}-r\right)\right) /\left(\mu_{e}\left(\mu_{d}+\right.\right.$ $\left.r)^{2}\left(g-\mu_{e}+p_{r}\right)\right)$ 
Theorem 4. If $m$ and other parameters satisfy one of the following two conditions, the retailer would chose $E B$ as his own e-market instead of ES:

(1)

$$
m<\frac{\mu_{e}-v}{\mu_{e}}
$$

(2)

$$
m>\frac{\mu_{e}+v}{\mu_{e}}-\kappa
$$

where $\kappa=(w-v)^{2}\left(p_{r}+g-\mu_{e}\right) /\left(\mu_{e}\left(\left(\mu_{e}-w\right)^{2}-\left(p_{r}+g-\right.\right.\right.$ $\left.\left.\left.\mu_{e}\right)\left(\mu_{e}+2 w-v\right)\right)\right)$.

From the above three theorems, it can be found that the choice of the retailer depends on the three parameters, that is, $\mu_{e}, \mu_{d}$, and $m$. However, the three parameters are interacted and none of them can determine the selection of the retailer alone. The interaction between e-market use fee and uncertain parameters is complicated. We explore the interaction between them by numerical experiments in the following section.

\section{Sensitivity Analysis}

In this section, we deploy the numerical experiment research to analyze the impacts of some parameters. The experiment data are assumed by ourselves. Although they are not real data from the reality, all of them are in reasonable range.

In the first three subsections we analyze the impact of parameters on the optimal order quantity in the case that demand and retail price in e-market are 2DU distributed. The numerical analysis in a more general case that demand $x$ and e-market price $p_{e}$ are BN distributed is also given to make a comparison with $2 \mathrm{DU}$ case. The changing trend of each kind of demand and e-market retail price distribution is roughly similar to that illustrated in figures. The three subsections are, respectively, about the impact of the customer demand, the impact of the retail price in e-market, and the impact of the e-market use fee. In these subsections, we analyze the model in which the supplier is the owner in EM.

In the last two subsections, we analyze parameters' impact on the selection of EB, ES, and EM when supplier or retailer builds his own e-market in the case that demand and retail price in e-market are 2DU distributed.

4.1. The Impact of the Customer Demand. Assuming that $\mu_{e}=$ $12, \sigma_{e}=2.5$, and $\mu_{d}=100$ and other parameters are set as follows: $p_{r}=30, w=10, g=20, v=6, \rho=0.2, M=200$, and $m=0.2$. Figure 1 shows that there is a positive relationship between customer demand variance and order quantity. It is due to high customer demand volatility that the retailer tends to order more products in traditional channel to meet the needs. When the order quantity exceeds the actual demand, excess inventory will be sold in e-market that can also ensure the increase of retailer's profit.

Assuming that $\mu_{e}=12, \sigma_{e}=2.5$, and $\sigma_{d}=25$, we can also find that there is an approximately linear relationship

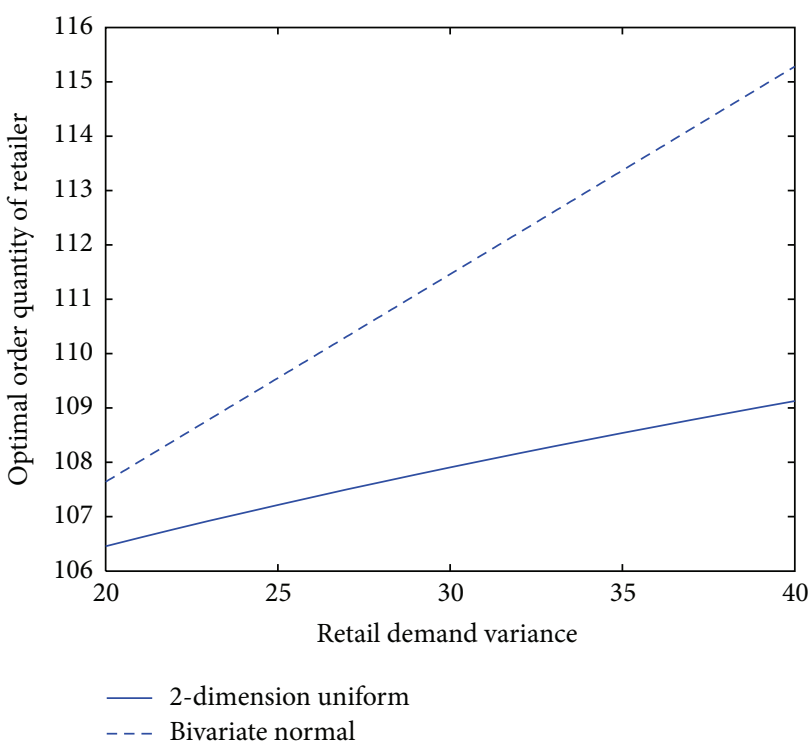

FIGURE 1: Changes of the order quantity with respect to the retail demand variance in EM.

between customer demand expectation and order quantity. So the figure is omitted.

In fact, the main source of retailer's profit is from traditional channel as we have supposed a lower retail price in e-market in this section. When the demand of traditional channel increases, retailer has an inevitable choice to increase order quantity to expand his income. Especially when the excess inventory can be sold in e-market, it is possible to pursuit more revenue.

4.2. The Impact of the Retail Price in E-Market. The parameters are reset as follows: $p_{r}=10, w=8, g=6, v=4, \mu_{d}=60$, and $\sigma_{d}=25$.

Figure 2 shows the relationship between order quantity and retail price expectation in EM. With the increase of retail price expectation, the order quantity also increases. This is because dramatic price fluctuations will make retailer's profit expectations get lower. This suggests that when a huge bubble merges in e-market, people should avoid entering into emarket.

4.3. The Impact of the Use Fee. In this part we discuss the relationship between order quantity and e-market use fee in e-market. The parameters are reset as follows: $\mu_{d}=100$, $\sigma_{d}=25, \mu_{e}=12$, and $\sigma_{e}=2.5$. Other parameters are the same as those in Section 4.1.

Figure 3 shows how the e-market use fee charged by emarket manager impacts order quantity in EM. It can be seen that the use fee affects order quantity negatively. When the e-market use fee ratio increases gradually, the retailer's order quantity declines slowly. Because the more e-market use fee is charged, the less the retailer trades in e-market till he quits entirely.

4.4. The Impact on the Selection of the Supplier. The parameters are set as follows: $p_{r}=50, w=30, g=20, v=20, r=20$, $c=18, \mu_{d}=100, m=0.1$, and $\mu_{e}=30$. 


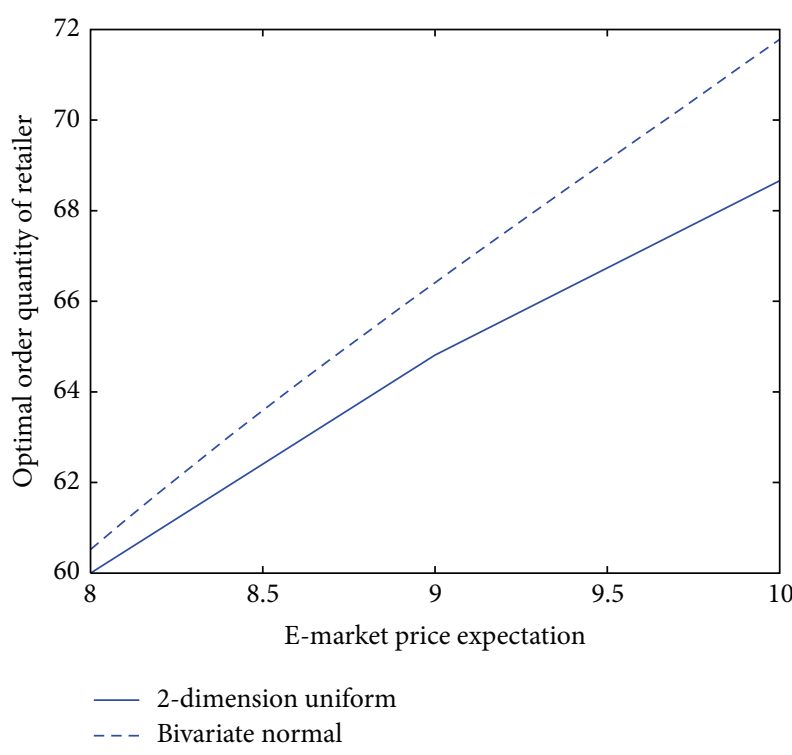

FIGURE 2: Changes of order quantity with respect to the retail price expectation in EM.

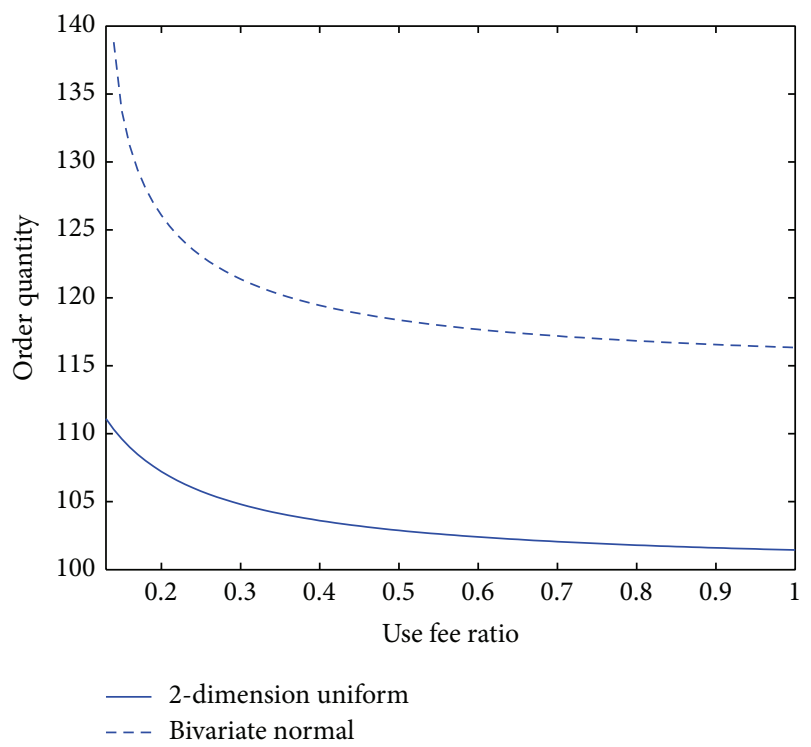

FIGURE 3: Changes of order quantity with respect to the e-market use fee ratio in EM.

Since the type of the e-market built by the supplier depends on $\mu_{e}, v$, and $m$, here we suppose that $v$ is a fixed amount and explore the relationship between $\mu_{e}, m$, and expected profit.

Figure 4 shows the changes of the expected profit difference of the supplier with respect to $\mu_{e}$ and $m$ when the supplier builds EB and EM. The horizontal grid in Figure 4 is the boundary in which the supplier chose EB or EM. The lines in $\mu_{e}-m$ plane are the contour line of profit difference. The contour line near $m=0.25$ is the one that supplier's expected profit difference is zero. If the profit difference is below the zero horizon or behind the zero contour line, the expected

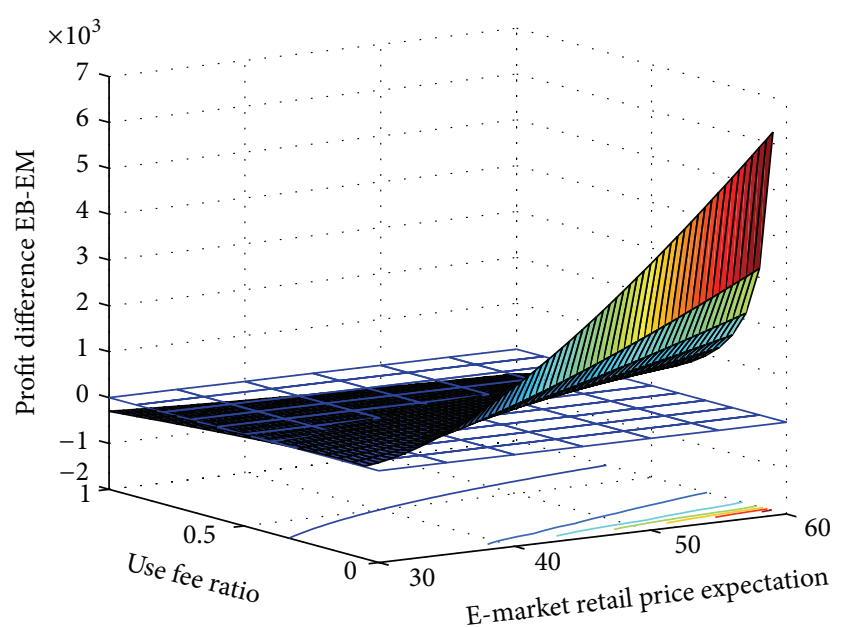

FIGURE 4: Changes of the expected profit difference of supplier in EB and EM with respect to $\mu_{e}$ and $m$.

profit in EB is less than that in EM. Hence the supplier would choose EM as his own e-market. When $\mu_{e}$ gets larger and $m$ gets smaller, the supplier will build EB as he can get more profit in EB than in EM. This is because that the retailer would order fewer products in traditional market to avoid the excess inventory and transfer to electronic platform for ordering if he cannot sell goods in e-market. Thus, the supplier can sell more products in e-market which is exactly the motivation of the supplier to close the selling channel for the retailer and only build an EB market. This result agrees with Theorem 1.

4.5. The Impact on the Selection of the Retailer. The choice of the retailer is more complicated than that of the supplier according to Theorems 2, 3, and 4 .

Figure 5 shows the changes of the retailer's expected profit with respect to $\mu_{e}$ in three different e-markets. It can be found that ES is the worst e-market under these initial conditions. There is a threshold point in EM as the retailer's expected profit is a piecewise function determined by $m$ and $4 r\left(\mu_{e}-w\right) /\left(\mu_{e}\left(\mu_{d}+r\right)\right)$. Before this point, there is a negative relationship between profit of EM and $\mu_{e}$. After this point, the profit in EM increases because the retailer can trade in EM completely. As for EB, the expected profit in it is decreasing with the retail price $\mu_{e}$. The profits in three e-markets indicate that the retailer should shut down the selling channel for more profit when $\mu_{e}$ is in a certain interval. This is because of the fact that opening selling channel can help manage the excess inventory or obtain more revenue when e-market retail price is too large or too small. But selling channel is not an advantage if the retailer making ordering strategy when $\mu_{e}$ is in a certain interval.

As the expected profit in ES is very low in these numerical conditions, we only explore the changes of the expected profit in EB and EM with respect to the demand expectation and variance. Figure 6 shows the changes of the expected profit of the retailer with respect to the mean value of demand $\mu_{d}$ and demand variance $r^{2} / 3$ in three different e-markets. The lines in expectation-variance plane are the contour line of profit 


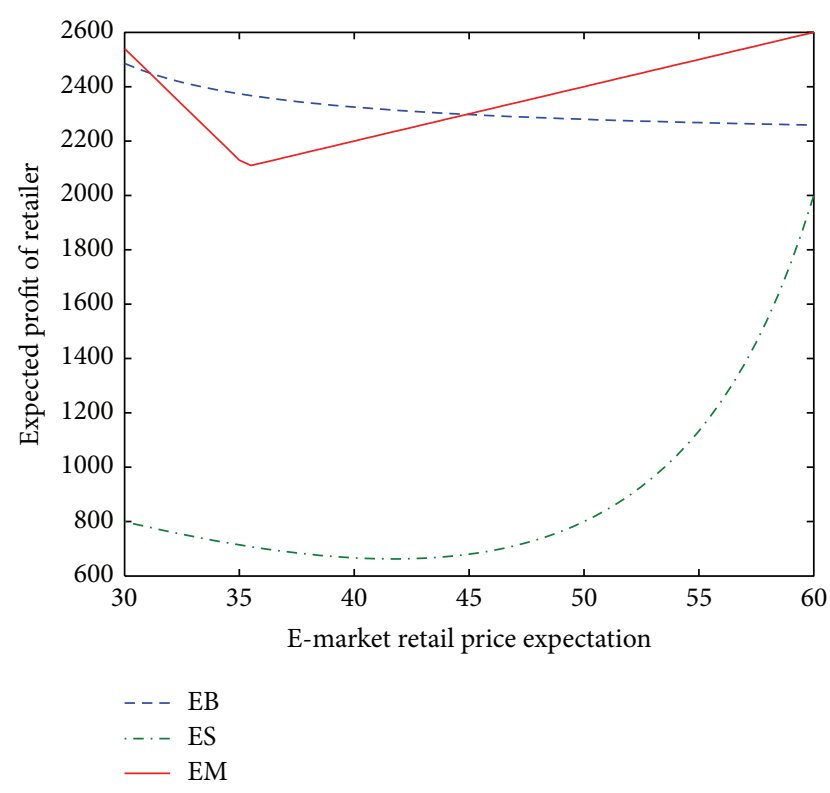

FIGURE 5: Changes of the retailer's expected profit with respect to $\mu_{e}$.

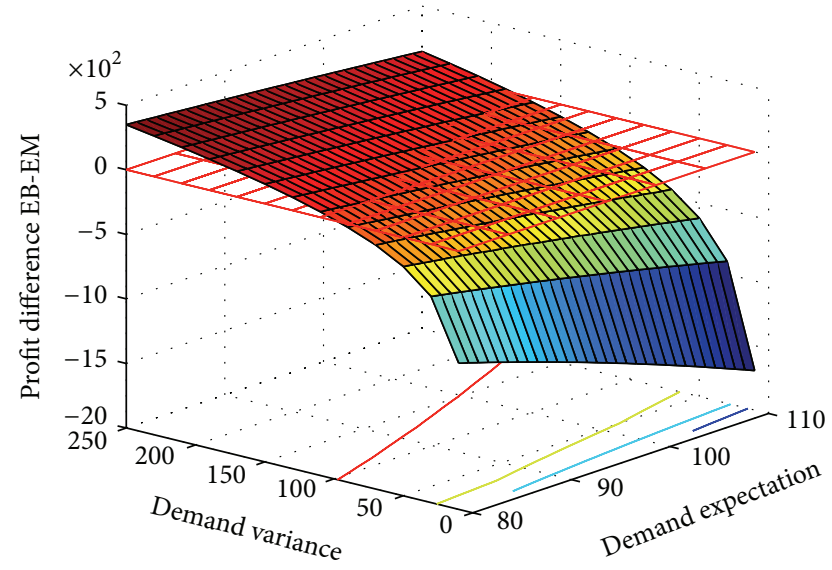

FIGURE 6: Changes of the expected profit difference of retailer in EB and EM with respect to $\mu_{d}$ and $r^{2} / 3$.

difference. The contour line near variance $=100$ is the decision boundary of the retailer. When demand expectation and demand variance are in the left side of this boundary in Figure 6, the retailer should choose EB from the calculation results. It illustrates that the choice between EB and EM mainly depends on the volatility of demand and is less affected by mean value of demand in this numerical case. If the volatility of demand is very big, the retailer should shut down the selling channel and order in traditional market according to the expected variance before selling season.

Figure 7 shows the changes of the expected profit of the retailer with respect to the e-market use fee ratio $m$ in three different e-markets. Parameter $m$ has no impact on the profit in ES which can also be observed in (19). There is a positive relationship between e-market use fee ratio and profit in EM. The profit function in EB is a nondecreasing convex function

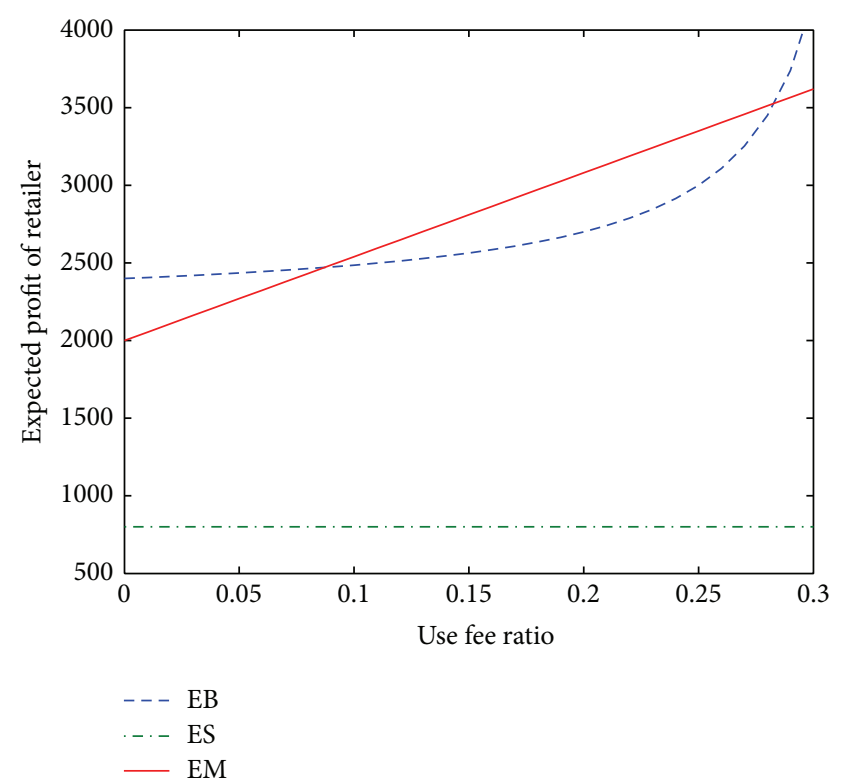

FIGURE 7: Retailer's expected profit changes with respect to e-market use fee ratio when he builds EB, ES, and EM.

of $m$. Since the retailer is the owner of e-market, he will earn more from the supplier who sells products via e-market if $m$ increases. The retailer should choose EM when the e-market use fee ratio is in a certain interval.

Through the above numerical examples, it can be found that the retailer's choice indeed depends on different product parameters. The key point of retailer's decision is the comparison of expected profits.

\section{Conclusions}

This paper develops some models to explore the issue of selection between several types of e-markets from the view point of supply chain. Besides demand uncertainty, we also take into account the price uncertainty in e-market. We explore the conditions under which the agent of supply chain selects one certain type of e-market by comparing expected profits of supply chain members in different scenarios in the case of customer demand and retail price following uniform distribution. Some sensitivity analyses are also conducted to explore the impact of the customer demand, e-market retail price, and e-market use fee on the optimal order quantity and on the selection of e-market in the case that demand $x$ and emarket price $p_{e}$ are $2 \mathrm{DU}$ and $\mathrm{BN}$. Our results demonstrate that the e-market use fee can be an important factor for assessing the performance of an e-market, and therefore is worth taking into consideration in the building of e-market. The main contribution of our paper is to obtain the additional revenue of the owner of the e-market. The cost of operating private e-market is a complicated value that contains multiple factors with specialized knowledge. If we can use a parameter to describe the operating cost, the comprehensive trade-off between different scenarios is straightforward by comparing the operating cost and the additional revenue. In this paper, 
the supplier's wholesale price and the retailer's retail price are assumed to be exogenous. If the retail price is ingenuous, the selection of the e-market in supply chain is a potential topic for future research. In addition, if the retailer can return the excess inventory to the supplier, it is another valuable research problem, that is, the buying-back option, for future research.

\section{Appendix}

\section{A. The Derivation of the Optimal Order Quantity in Different Scenarios}

Proof. When demand and retail price in e-market are $\mathrm{BN}$ distributed, the optimal order quantity satisfies the following equations.

In public EB, the optimal order quantity is given by

$$
\begin{aligned}
F_{d}\left(q_{\mathrm{EB}}^{*}\right)= & \frac{(1+m) f_{d}\left(q_{\mathrm{EB}}^{*}\right)}{-v+(1+m) \mu_{e}}\left(2 \mu_{d} \mu_{e}-2 q_{\mathrm{EB}}^{*} \mu_{e}+\rho \sigma_{d} \sigma_{e}\right) \\
& +\frac{-w+(1+m) \mu_{e}}{-v+(1+m) \mu_{e}} .
\end{aligned}
$$

As the retailer is the owner of a private $\mathrm{EB}$, the optimal order quantity is given by

$$
\begin{aligned}
F_{d}\left(q_{\mathrm{EB}}^{*}\right)= & \frac{f_{d}\left(q_{\mathrm{EB}}^{*}\right)}{-v+\mu_{e}}\left(2 \mu_{d} \mu_{e}-2 q_{\mathrm{EB}}^{*} \mu_{e}+\rho \sigma_{d} \sigma_{e}\right) \\
& +\frac{-w+\mu_{e}}{m p_{r}-v+\mu_{e}} .
\end{aligned}
$$

In public ES, the optimal order quantity is given by

$$
\begin{aligned}
F_{d}\left(q_{\mathrm{ES}}^{*}\right)= & -\frac{f_{d}\left(q_{\mathrm{ES}}^{*}\right)}{p_{r}+g-(1-m) \mu_{e}}\left(2 \mu_{d} \mu_{e}-2 q_{\mathrm{ES}}^{*} \mu_{e}+\rho \sigma_{d} \sigma_{e}\right) \\
& +\frac{p_{r}+g-w}{p_{r}+g-(1-m) \mu_{e}} .
\end{aligned}
$$

As the retailer is the owner of a private ES, the optimal order quantity is given by

$$
\begin{aligned}
F_{d}\left(q_{\mathrm{ES}}^{*}\right)= & -\frac{f_{d}\left(q_{\mathrm{ES}}^{*}\right)}{p_{r}+g-\mu_{e}}\left(2 \mu_{d} \mu_{e}-2 q_{\mathrm{ES}}^{*} \mu_{e}+\rho \sigma_{d} \sigma_{e}\right) \\
& +\frac{p_{r}+g-w}{p_{r}+g-\mu_{e}} .
\end{aligned}
$$

In public EM, the optimal order quantity is given by

$$
\begin{aligned}
F_{d}\left(q_{\mathrm{EM}}^{*}\right)= & \frac{f_{d}\left(q_{\mathrm{EM}}^{*}\right)}{\mu_{e}}\left(2 \mu_{d} \mu_{e}-2 q_{\mathrm{EM}}^{*} \mu_{e}+\rho \sigma_{d} \sigma_{e}\right) \\
& +\frac{-w+\mu_{e}(1+m)}{2 m \mu_{e}} .
\end{aligned}
$$

As the retailer is the owner of a private EM, the optimal order quantity is given by

$$
\begin{aligned}
F_{d}\left(q_{\mathrm{EM}}^{*}\right)= & \frac{f_{d}\left(q_{\mathrm{EM}}^{*}\right)}{\mu_{e}}\left(2 \mu_{d} \mu_{e}-2 q_{\mathrm{EM}}^{*} \mu_{e}+\rho \sigma_{d} \sigma_{e}\right) \\
& +\frac{\mu_{e}-w}{2 \mu_{e}} .
\end{aligned}
$$

Proof of Theorem 1. When the supplier is the owner of EB and EM, the difference of his optimal expected profit between EB and $\mathrm{EM}$ is given by

$$
\Pi_{\mathrm{EB}}^{S *}-\Pi_{\mathrm{EM}}^{S *}=\frac{r\left(w-(1+m) \mu_{e}\right)^{2}\left(v-(1-m) \mu_{e}\right)}{m \mu_{e}\left(v-(1+m) \mu_{e}\right)} .
$$

Notice that $\left(w-(1+m) \mu_{e}\right)^{2}>0$ and $v-(1+m) \mu_{e}<0$, and the sign of $\Pi_{\mathrm{EB}}^{S *}-\Pi_{\mathrm{EM}}^{S *}$ is the same with $v-(1-m) \mu_{e}$, that is, $m-\left(1-\left(v / \mu_{e}\right)\right)$. The proof is completed.

Proof of Theorem 2. There are two cases when the retailer compares the profits in EB and EM.

Case 1. When $m<4 r\left(\mu_{e}-w\right) /\left(\mu_{e}\left(\mu_{d}+r\right)\right)$, the difference of retailer's optimal expected profit between EM and EB is given by

$$
\Pi_{\mathrm{EM}}^{R *}-\Pi_{\mathrm{EB}}^{R *}=r\left(\mu_{e}+v-2 w\right)+\frac{r(v-w)^{2}}{v-(1-m) \mu_{e}} .
$$

Solving inequality $\Pi_{\mathrm{EM}}^{R *}-\Pi_{\mathrm{EB}}^{R *}>0$, the following solution sets are obtained.

(1) Consider the following:

$$
\begin{gathered}
\mu_{e}+v-2 w<0, \\
\frac{\mu_{e}-v}{\mu_{e}}<m<\frac{4 w v+\mu_{e}^{2}-2 v^{2}-w^{2}-2 w \mu_{e}}{\mu_{e}\left(\mu_{e}+v-2 w\right)} .
\end{gathered}
$$

(2) Consider the following:

$$
\begin{gathered}
\mu_{e}+v-2 w>0, \\
m>\frac{\mu_{e}-v}{\mu_{e}} .
\end{gathered}
$$

(3) Consider the following:

$$
\begin{gathered}
\mu_{e}+v-2 w>0 \\
m<\frac{4 w v+\mu_{e}^{2}-2 v^{2}-w^{2}-2 w \mu_{e}}{\mu_{e}\left(\mu_{e}+v-2 w\right)} .
\end{gathered}
$$

Since $\Pi_{\mathrm{EB}}^{R *}$ is calculated in the condition that $\Pi_{\mathrm{EB}}^{R *}$ is concave with $q_{\mathrm{EB}}^{*}, m<\left(\mu_{e}-v\right) / \mu_{e}$ must be true. And when $\mu_{e}+v-2 w>0$, there is $\left(4 w v+\mu_{e}^{2}-2 v^{2}-w^{2}-2 w \mu_{e}\right) /\left(\mu_{e}\left(\mu_{e}+\right.\right.$ $v-2 w))<\left(\mu_{e}-v\right) / \mu_{e}$. Therefore, conditions (1) and (2) are 
rejected. In this case, conditions where the retailer chooses EM as his own e-market can be formulated as follows:

(4) Consider the following:

$$
\begin{gathered}
\mu_{e}+v-2 w>0, \\
m<\frac{4 w v+\mu_{e}^{2}-2 v^{2}-w^{2}-2 w \mu_{e}}{\mu_{e}\left(\mu_{e}+v-2 w\right)} \wedge \frac{4 r\left(\mu_{e}-w\right)}{\mu_{e}\left(\mu_{d}+r\right)} .
\end{gathered}
$$

Case 2. When $m>4 r\left(\mu_{e}-w\right) /\left(\mu_{e}\left(\mu_{d}+r\right)\right)$, the difference of retailer's optimal expected profit between EM and EB is given by

$$
\Pi_{\mathrm{EM}}^{R *}-\Pi_{\mathrm{EB}}^{R *}=\frac{\alpha m^{2}+\beta m+\gamma}{4 r\left(m \mu_{e}+v-\mu_{e}\right)},
$$

where $\alpha=\mu_{d}^{2} \mu_{e}^{2}+2 r \mu_{d} \mu_{e}^{2}+\mu_{e}^{2} r^{2}>0$.

When $\Delta=\beta^{2}-4 \alpha \gamma<0$, EM is always better than EB.

When $\Delta=\beta^{2}-4 \alpha \gamma>0$, the two solutions of $\alpha m^{2}+\beta m+$ $\gamma=0$ are $\left(-\beta-\sqrt{\beta^{2}-4 \alpha \gamma}\right) / 2 \alpha$ and $\left(-\beta+\sqrt{\beta^{2}-4 \alpha \gamma}\right) / 2 \alpha$. The following solution set can be obtained after sovling inequality $\Pi_{\mathrm{EM}}^{R *}-\Pi_{\mathrm{EB}}^{R *}>0$ and condition (6) is also rejected because $m<\left(\mu_{e}-v\right) / \mu_{e}$.

(5) Consider the following:

$$
\begin{aligned}
& m>\frac{4 r\left(\mu_{e}-w\right)}{\mu_{e}\left(\mu_{d}+r\right)}, \\
& m<\min \left(\frac{\mu_{e}-v}{\mu_{e}}, \frac{-\beta+\sqrt{\beta^{2}-4 \alpha \gamma}}{2 \alpha}\right) .
\end{aligned}
$$

(6) Consider the following:

$$
m>\max \left(\frac{4 r\left(\mu_{e}-w\right)}{\mu_{e}\left(\mu_{d}+r\right)}, \frac{\mu_{e}-v}{\mu_{e}}, \frac{-\beta+\sqrt{\beta^{2}-4 \alpha \gamma}}{2 \alpha}\right) .
$$

Summarizing the two cases, the retailer should choose EM under the conditions (4) and (5) or he should choose EB as his own e-market. Thus, the proof is completed.

Proof of Theorem 3. There are also two cases when the retailer compares the profits in EM and ES.

Case 1. When $m<4 r\left(\mu_{e}-w\right) /\left(\mu_{e}\left(\mu_{d}+r\right)\right)$, the difference of the retailer's optimal expected profit between EM and ES is given by

$$
\Pi_{\mathrm{EM}}^{R *}-\Pi_{\mathrm{ES}}^{R *}=2 \mu_{e} r-\frac{r\left(\mu_{e}-w\right)^{2}}{g-\mu_{e}+p_{r}} .
$$

If parameters satisfy the following conditions, $\Pi_{\mathrm{EM}}^{R *}-$ $\Pi_{\mathrm{ES}}^{R *}>0$.

(1) Consider the following:

$$
m<\frac{4 r\left(\mu_{e}-w\right)}{\mu_{e}\left(\mu_{d}+r\right)}, \quad 2 \mu_{e} r>\frac{r\left(\mu_{e}-w\right)^{2}}{g-\mu_{e}+p_{r}} .
$$

Case 2. When $m>4 r\left(\mu_{e}-w\right) /\left(\mu_{e}\left(\mu_{d}+r\right)\right)$, the difference of retailer's optimal expected profit between EM and ES is given by

$$
\begin{aligned}
\Pi_{\mathrm{EM}}^{R *}-\Pi_{\mathrm{ES}}^{R *}= & w\left(\mu_{d}+r\right)-\mu_{e}\left(\mu_{d}-r\right) \\
& +\frac{m \mu_{e}\left(\mu_{d}+r\right)^{2}}{4 r}-\frac{r\left(\mu_{e}-w\right)^{2}}{g-\mu_{e}+p_{r}} .
\end{aligned}
$$

$\Pi_{\mathrm{EM}}^{R *}-\Pi_{\mathrm{ES}}^{R *}>0$ results in the following condition:

$$
m>\frac{4 r\left(\left(\mu_{e}-w\right)^{2}+w\left(\mu_{d}+r\right)-\mu_{e}\left(\mu_{d}-r\right)\right)}{\mu_{e}\left(\mu_{d}+r\right)^{2}\left(g-\mu_{e}+p_{r}\right)} .
$$

In the condition, we obtain another inequality (A.19). So the final range of in this case is condition (2) as there should be a join between and inequality (A.19).

Equivalently, in this case only the parameters satisfy condition (2) should the retailer choose EM as his own e-market.

(2) Consider the following:

$$
m>\frac{4 r\left(\mu_{e}-w\right)}{\mu_{e}\left(\mu_{d}+r\right)} \vee \eta
$$

where $\eta=4 r\left(\left(\mu_{e}-w\right)^{2}+w\left(\mu_{d}+r\right)-\mu_{e}\left(\mu_{d}-r\right)\right) /\left(\mu_{e}\left(\mu_{d}+\right.\right.$ $\left.r)^{2}\left(g-\mu_{e}+p_{r}\right)\right)$.

In the case and, we obtain condition (1) and condition (2). To sum up, a union result of the two conditions is the theorem condition.

Proof of Theorem 4. When the retailer makes a choice between EB and ES, the optimal profit difference is given by

$$
\begin{aligned}
\Pi_{\mathrm{EB}}^{R *}-\Pi_{\mathrm{ES}}^{R *}= & r\left(w+\mu_{e}\right)-r(v-w) \\
& +\frac{r\left(\mu_{e}-w\right)^{2}}{\mu_{e}-g-p_{r}}+\frac{r(v-w)^{2}}{(1-m) \mu_{e}-v} .
\end{aligned}
$$

While $\Pi_{\mathrm{EB}}^{R *}$ and $\Pi_{\mathrm{ES}}^{R *}$ are concave with $q_{\mathrm{EB}}^{*}$ and $q_{\mathrm{ES}}^{*}, m<\left(\mu_{e}-\right.$ $v) / \mu_{e}$ and $g+p_{r}-\mu_{e}>0$ are true. The following constraint of $m$ can be easily derived by $\Pi_{\mathrm{EB}}^{R *}-\Pi_{\mathrm{ES}}^{R *}>0$.

(1) Consider the following:

$$
m>\frac{\mu_{e}+v}{\mu_{e}}-\kappa
$$

where we denote $\kappa \triangleq(w-v)^{2}\left(p_{r}+g-\mu_{e}\right) / \mu_{e}\left(\left(\mu_{e}-w\right)^{2}-\left(p_{r}+\right.\right.$ $\left.\left.g-\mu_{e}\right)\left(\mu_{e}+2 w-v\right)\right)$. As we do not know the value of $\left(\mu_{e}-v\right) / \mu_{e}$ and $\left(\left(\mu_{e}+v\right) / \mu_{e}\right)-\kappa$, the final condition that retailer chooses $\mathrm{EB}$ as his own e-market is

$$
m>\frac{\mu_{e}+v}{\mu_{e}}-\kappa
$$

or

$$
m<\frac{\mu_{e}-v}{\mu_{e}}
$$

Then the proof is completed. 


\section{Conflict of Interests}

The authors declare that there is no conflict of interests regarding the publication of this paper.

\section{Acknowledgments}

The authors would like to thank the editor and two anonymous reviewers for their valuable and constructive comments, which have led to significant improvements in the paper. This research was supported in part by the National Natural Science Foundation of China under Grant nos. 71171011 and 91224001 and the New Century Excellent Talents in Universities scheme (NCET-12-0756). This paper is the extended version of an early and simplified version that appeared in the proceedings of CSO2011 and BIFE2012.

\section{References}

[1] V. Kumar and E. G. Raheja, "Business to business (b2b) and business to consumer (b2c) management," International Journal of Computers \& Technology, vol. 3, no. 3, pp. 447-551, 2012.

[2] B. Peleg, H. L. Lee, and W. H. Hausman, "Short-term E-procurement strategies versus long-term contracts," Production and Operations Management, vol. 11, no. 4, pp. 458-479, 2002.

[3] R. W. Seifert, U. W. Thonemann, and W. H. Hausman, "Optimal procurement strategies for online spot markets," European Journal of Operational Research, vol. 152, no. 3, pp. 781-799, 2004.

[4] T. Choi, D. Li, and H. Yan, "Optimal returns policy for supply chain with e-marketplace," International Journal of Production Economics, vol. 88, no. 2, pp. 205-227, 2004.

[5] R. Ganeshan, T. Boone, and P. Aggarwal, "Optimal procurement portfolios when using B2Bs: a model and analysis," International Journal of Production Economics, vol. 118, no. 1, pp. 146-151, 2009.

[6] S. Standing, C. Standing, and P. E. D. Love, "A review of research on e-marketplaces 1997-2008," Decision Support Systems, vol. 49, no. 1, pp. 41-51, 2010.

[7] S. Khanam, "A study of b2c websites and traditional store in Bangladesh," Daffodil International University, 2012.

[8] Z. Ning, T. Choi, C. Xie, L. Xie, and J. Dai, "Impact of e-marketplace on supply chain under the markdown policy," Supply Chain Management: An International Journal, vol. 16, no. 6, pp. 409-418, 2011.

[9] J. Kacen, J. D. Hess, and W. Y. K. Chiang, "Bricks or clicks? Consumer attitudes toward traditional stores and online stores," Global Economics and Management Review, vol. 18, no. 1, pp. 1221, 2013.

[10] M. Narenji, M. Fathian, E. Teimoury, and S. G. J. Naini, "Price and delivery time analyzing in competition between an electronic and a traditional supply chain," Mathematical Problems in Engineering, vol. 2013, Article ID 596897, 12 pages, 2013.

[11] M. Maity and M. Dass, "Consumer decision-making across modern and traditional channels: E-commerce, M-commerce, in-store," Decision Support Systems, vol. 61, pp. 34-46, 2014.

[12] C. X. Wang and M. Benaroch, "Supply chain coordination in buyer centric B2B electronic markets," International Journal of Production Economics, vol. 92, no. 2, pp. 113-124, 2004.
[13] A. Ghose and Y. Yao, "Using transaction prices to re-examine price dispersion in electronic markets," Information Systems Research, vol. 22, no. 2, pp. 269-288, 2011.

[14] K. Inderfurth, P. Kelle, and R. Kleber, "Dual sourcing using capacity reservation and spot market: optimal procurement policy and heuristic parameter determination," European Journal of Operational Research, vol. 225, no. 2, pp. 298-309, 2013.

[15] T. H. Shon, C. Parker, and P. Swatman, "Classifying Australian B2B imarketplaces: an Australian survey," in Proceedings of the 14th Australasian Conference on Information Systems: Delivering IT and e-Business Value in Networked Environments (ACIS '03), pp. 1-11, Perth, Western Australia, November 2003.

[16] W. Xing, S. Wang, and G. Feng, "Game analysis on supply chain with B2B electronic marketplace," Systems Engineering Theory and Practice, vol. 7, pp. 56-60, 2008.

[17] D. Truong, T. T. Le, S. Senecal, and S. S. Rao, "Electronic marketplace: a distinct platform for business-to-business (B-to-B) procurement," Journal of Business-to-Business Marketing, vol. 19, no. 3, pp. 216-247, 2012.

[18] J. Pei, J. Li, X. Tian, and Y. Ding, "Optimal strategies of supply chain with uncertain electronic market price," in Proceedings of the 4th International Joint Conference on Computational Sciences and Optimization (CSO '11), pp. 431-435, Yunnan, China, April 2011.

[19] J. Li, J. Pei, F. Yang, and Y. Wang, "Public or private? An analysis of supply chain choice of e-markets," in Proceedings of the 5th International Conference on Business Intelligence and Financial Engineering (BIFE '12), pp. 113-117, August 2012.

[20] K. Fu, J. Xu, and Z. Miao, "Newsvendor with multiple options of expediting," European Journal of Operational Research, vol. 226, no. 1, pp. 94-99, 2013.

[21] K. Fu, V. N. Hsu, and C. Lee, "Note optimal component acquisition for a single-product, single-demand assemble-to-order problem with expediting," Manufacturing and Service Operations Management, vol. 11, no. 2, pp. 229-236, 2009.

[22] H. Mamani and K. Moinzadeh, "Lead time management through expediting in a continuous review inventory system," Production and Operations Management, vol. 23, no. 1, pp. 95109, 2014 


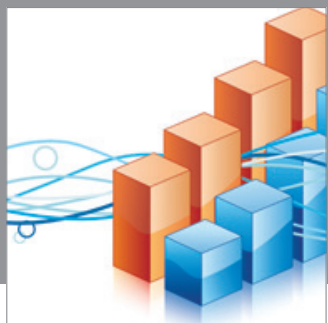

Advances in

Operations Research

mansans

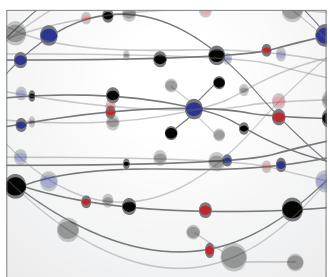

The Scientific World Journal
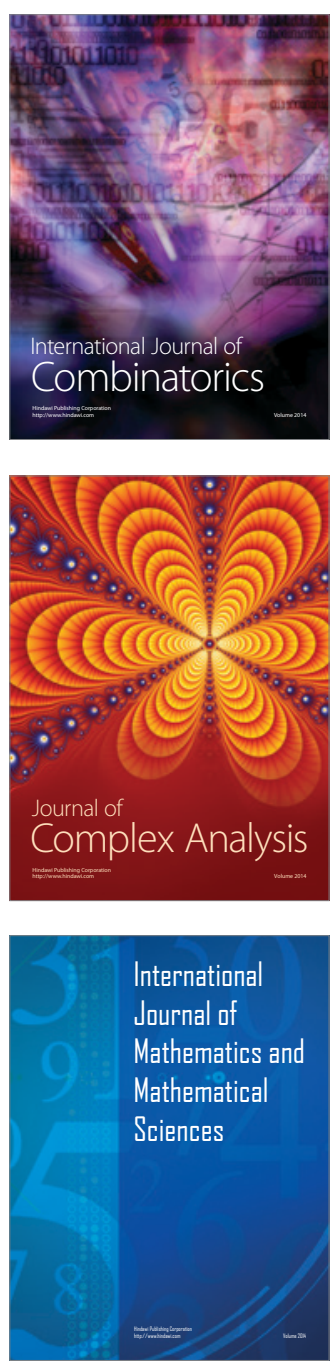
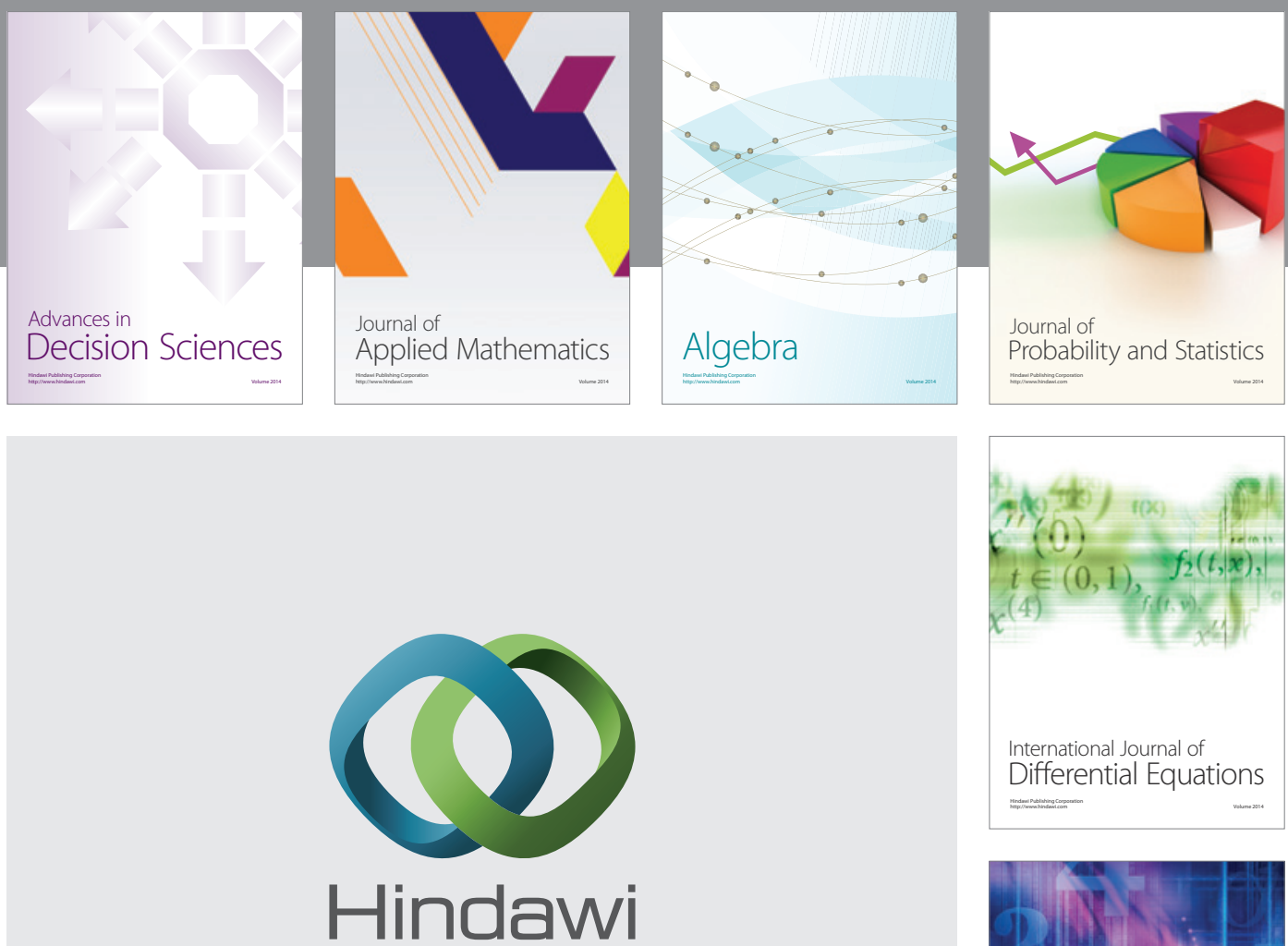

Submit your manuscripts at http://www.hindawi.com
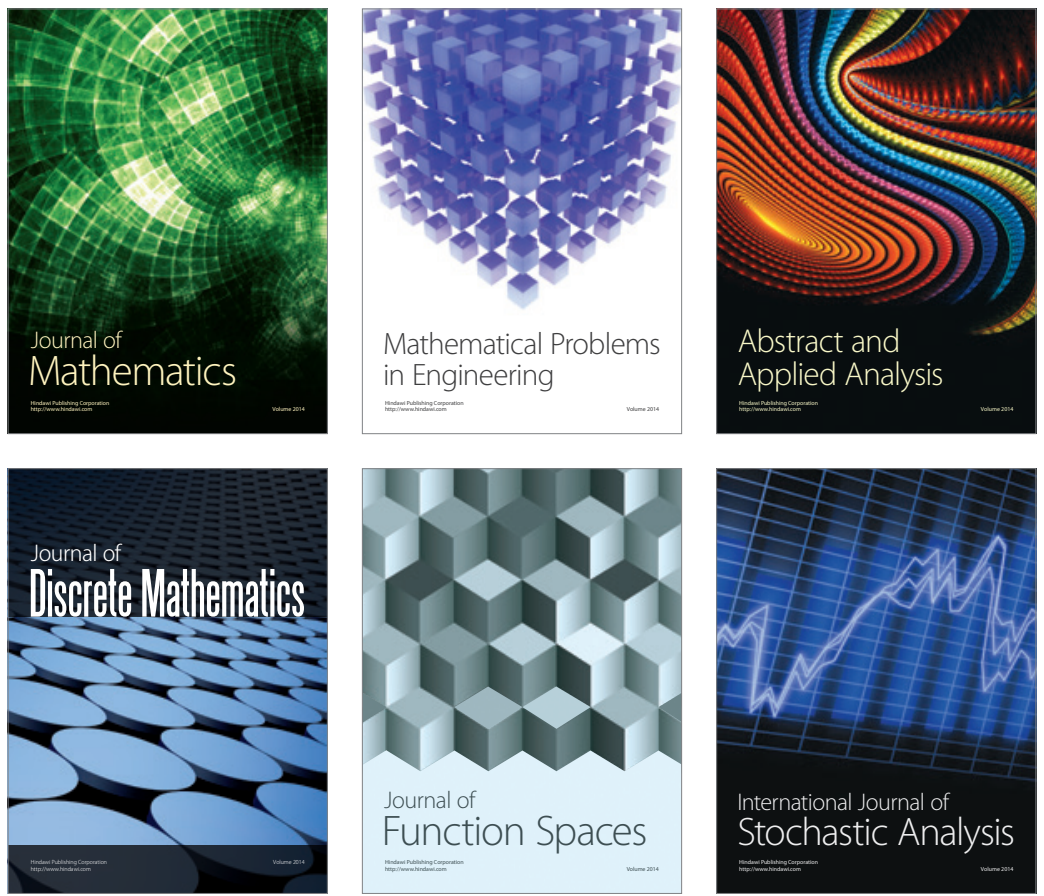

Journal of

Function Spaces

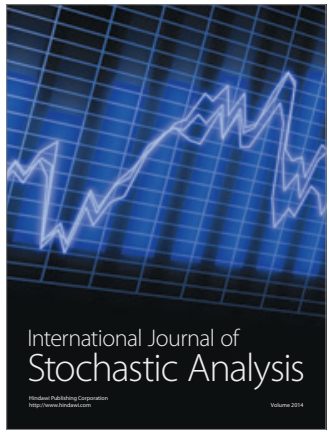

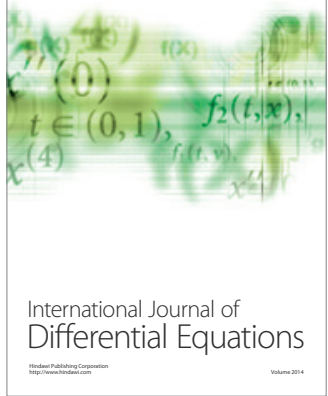
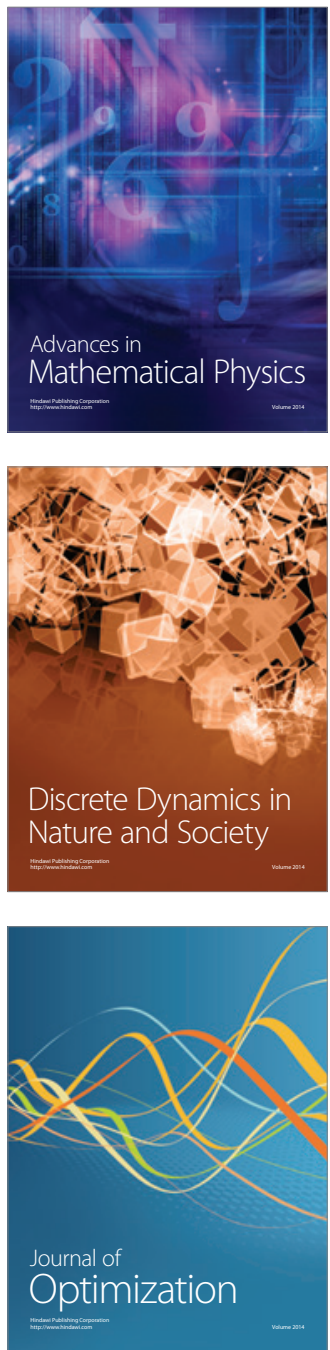